\title{
Psy-Kongress - Tagungsbericht
}

Bern, 5.-7. September 2018

Peter Schulthess

Der Psy-Kongress wurde von der Schweizerischen Gesellschaft für Psychiatrie und Psychotherapie (SGPP) in Partnerschaft mit ASP, FSP und SBAP organisiert. 1.200 Personen nahmen teil, davon leider gerade mal ein Dutzend ASP-Mitglieder. Der Grossteil der Teilnehmenden stammte aus der SGPP, deren Jahreskongresse immer um die 1.000 PsychiaterInnen anziehen. Warum nur so wenige aus unserem Verband? Schreckte die Psychiatrie-Dominanz ab? Die Industrieausstellung mit den vielen Pharma-Ständen war in der Tat für psychologische PsychotherapeutInnen eher abschreckend. Umso mehr wollen wir in der à jour! über den Kongress berichten, damit auch die Mitgliederbasis etwas über dessen Inhalte erfährt. Denn es gab nebst den Psychiatrie- und Pharma-lastigen Präsentationen auch sehr wertvolle Beiträge zur Psychotherapie.

In Ergänzung zu dem, was bereits im Bericht der Präsidentin ausgeführt wurde, berichte ich über weitere Veranstaltungen.

Gleich zu Beginn des Kongresses referierte Peter Ventevogel vom United Nations High Commissioner for Refugees (UNHCR) in Genf zum Thema «Mental Health of Refugees in Global Perspective». 1 Prozent der Weltbevölkerung sei von erzwungener Dislokation betroffen, worunter es 22,5 Millionen Flüchtlinge gäbe. Die meisten würden aus low-income Staaten stammen, wo auch kaum Ressourcen für mental health care vorhanden seien. Die grosse Angebotslücke in armen Ländern und Krisengebieten verlange viel mehr als spezialisierte Kenntnisse und Techniken von Professionellen. Drei Entwicklungen würden sich abzeichnen:

1. Community-bezogene Ansätze, die Selbsthilfe-Ressourcen nutzen und die soziale Einbindung stärken.

2. Kurzpsychotherapie-Interventionen, welche auch von nicht professionellen HelferInnen eingesetzt werden, die man trainiert und supervidiert.

3. Integration von mental health care in die generelle health care von Flüchtlingen.

Abends hielt im Anschluss an die offizielle Kongresseröffnung Dirk Helbling, Professor am Departement für Computerwissenschaften, an der ETH-Tagung einen Vortrag zum «Einsatz von Cognitive Computing in der Psychotherapie: Chancen und Risiken». Seine Ausführungen waren so brisant, dass sie unter der Rubrik
«Fokus» in diesem Heft speziell zusammengefasst werden. Er führte erst durch die Welt des Big Data-Sammelns (vgl. auch mit dem Beitrag von Marianne Roth über Fake News) zum Datensammeln im Gesundheitswesen generell und schliesslich zu den Anwendungen in der Psychotherapie und besprach Chancen und Risiken dieser auf uns zukommenden Datenwelt.

Spannend war auch das Plenarreferat von Katharina Domschke, Freiburg im Breisgau, zum Thema «Epigenetik - der zweite Code bei psychischen Erkrankungen». Epigenetik ist das Fachgebiet der Biologie, das sich mit der Frage befasst, welche Faktoren die Aktivität eines Gens und damit die Entwicklung der Zelle zeitweilig festlegen. Epigenetische Mechanismen wie DNA-Methylierung rücken als biochemisches «Scharnier» zwischen «nature〉 und «nurture» in der Psychiatrie und Psychologie zunehmend in den Fokus der Aufmerksamkeit. Tatsächlich erlaubt die Epigenetik selbst subtilen Umweltveränderungen den Zugriff auf unser Erbgut neue Forschung zeigt, dass die Entstehung von Krankheiten oder die Veränderung von Persönlichkeitsmerkmalen epigenetisch beeinflusst sein können - ein wichtiger Gegenbefund zur These, dass alles in unseren Genen angelegt und somit unabänderlich sei! Auch Beziehungserfahrungen in einer Psychotherapie sind solche Umweltfaktoren, die dazu beitragen können, ob genetische Anlagen zur Wirkung kommen oder nicht.

Ein weiteres Plenarreferat war aufschlussreich. Jens Gaab, Basel, gab seinem Beitrag zum Stand der Psychotherapieforschung einen speziellen

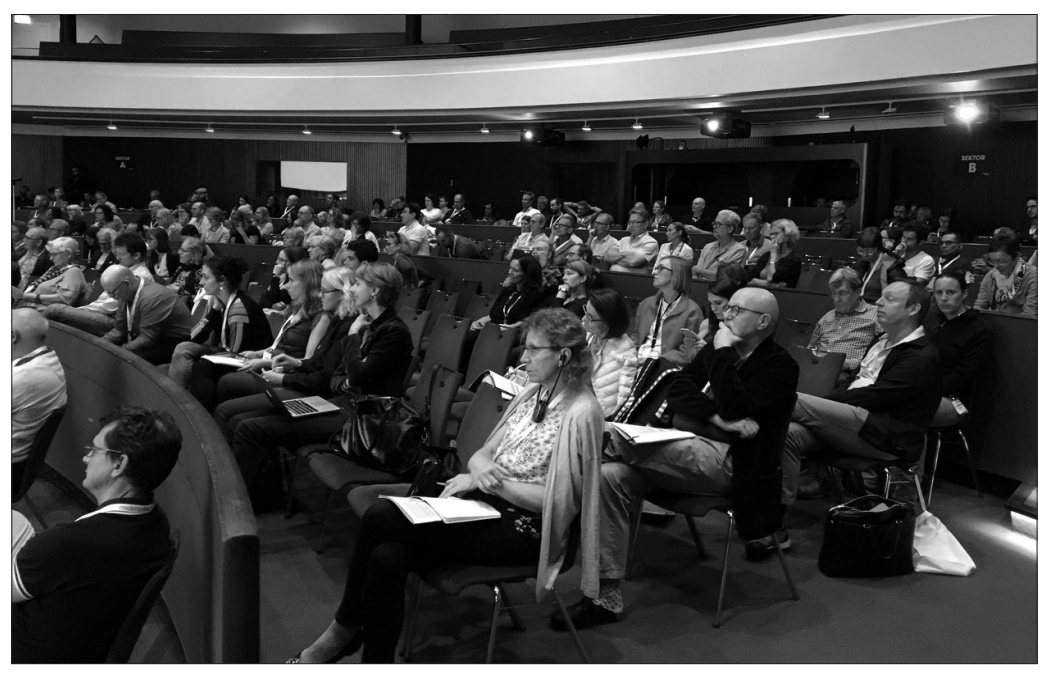

Interessierte Hörerschaft

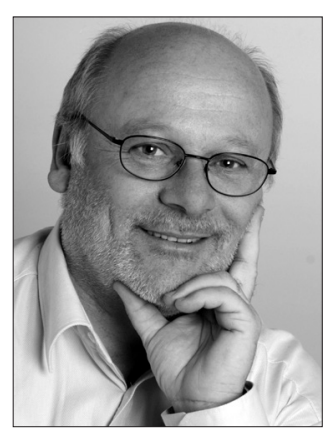

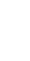


Titel: «Die Spitze des Eisbergs und der Rest - von ausgestorbenen Vögeln, Benjamin Franklin und Stradivari und was das mit Psychotherapie zu tun hat». Er referierte zu den angenommen Wirkfaktoren seit der Entstehung der Psychotherapie mit der Magnetismus-Theorie von Mesmer bis heute, referierte über Ergebnisse der Placeboforschung und stellte diese in Zusammenhang mit der Psychotherapie. Was ist das Verum in der Psychotherapie? Was ist Placebo? Er kritisierte die psychologische Forschung dahingehend, dass oft nur die beobachtbare, sichtbare Spitze des Eisberges untersucht würde, den grossen Rest lasse man unbeachtet. Dabei sei doch die Titanic wegen der Kollision mit dem nicht sichtbaren Teil untergangen, nicht wegen der Spitze des Eisberges, meinte er metaphorisch. Auch seinen Ausführungen ist ein spezieller Beitrag unter der Rubrik «Fokus» in diesem Heft gewidmet.

Neben den sechs Hauptvorträgen gab es auch zehn «State of the Art» Vorträge und Parallelveranstaltungen mit Vorträgen, Workshops oder Symposien bzw. Panels zu unzähligen Themen. Die Veranstaltungen waren allesamt auf einem guten Niveau.

Durch den ganzen Kongress zog sich ein besonderes Thema in täglichen Open Space-Veranstaltungen, welche dem Umstand Rechnung trugen, dass diese Psy-Tagung nicht bloss die Jahrestagung der Schweizer PsychiaterInnen war, sondern eben auch von den Verbänden ASP, FSP und SBAP mitorganisiert wurde.

Die zentrale Frage lautete: «Psychiatrie UND Psychologie: Kooperation UND Konkurrenz zu Gunsten der Versorgung psychisch kranker Menschen - wie gestalten wir dies konkret?» Leider wurden diese Open Space-Veranstaltungen wenig beachtet und besucht. In einer Plenarveranstaltung wurde über Ergebnisse berichtet, sowie ein abschliessendes Panel mit VertreterInnen der Verbände gehalten.

Seitens der PatientInnen wurde eingefordert, mit Fachleuten in Kontakt kommen zu können und einen leichten Zugang zur Psychotherapie zu erhalten, als Arbeit in einer Beziehungserfahrung

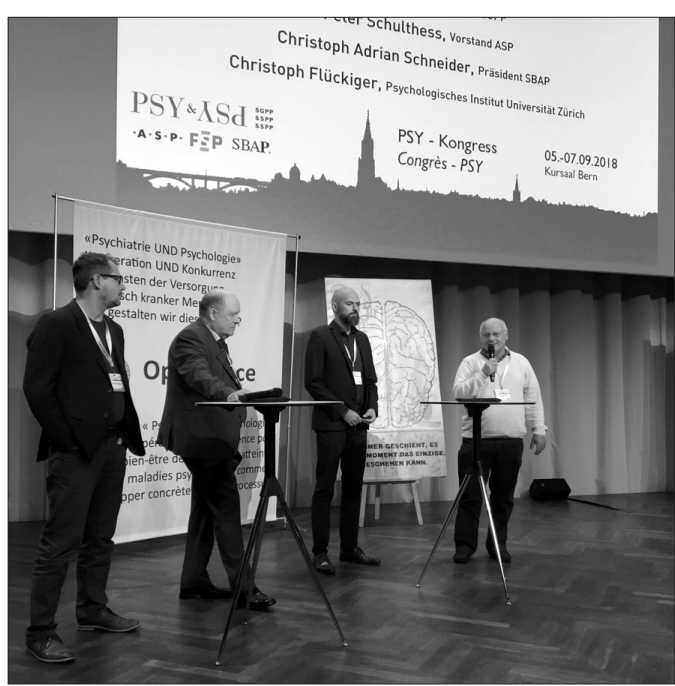

(v.l.) Christoph Flückiger (FSP/Uni Zürich), Pierre Vallon (SGPP), Christoph Adrian Schneider (SBAP), Peter Schulthess (ASP)

und nicht bloss mit Pillen abgefüttert zu werden. Seitens der SGPP wurde betont, wie sehr den PsychiaterInnen an der Zusammenarbeit mit den PsychologInnen läge und dies doch in der Praxis über die delegierte Therapie recht gut funktioniere. Seitens der Psychotherapieverbände wurde moniert, dass es gleich lange Spiesse brauche, um auf Augenhöhe kooperieren zu können: gleiche Honorierung für die gleiche Leistung, wenn es um Durchführung von Psychotherapie geht. Das Delegationsmodell mit dem damit verbundenen Anstellungsverhältnis sei abzulösen wenigstes durch ein Anordnungsmodell. Die Psychotherapieverbände waren sich einig, dass man lauter werden als bisher und die derzeitige Sackgasse mit dem Tarmed und der ungerechten Geldverteilung innerhalb der FMH, dem Spardruck von Santésuisse, überwinden müsse. Die Hinhaltetaktik des BAG, die auch beim von Gabriela Rüttimann beschriebenen Panel zum Ausdruck kam, sei aufzubrechen mit verschiedenen Massnahmen: Rechtsweg, Petition, neue Versicherungsmodelle, Demonstrationen.

Peter Schulthess ist Vorstandsmitglied der ASP. 